\title{
灌浆施工技术在水库施工中的有效应用
}

\author{
申慧
}

中工武大设计研究有限公司新疆分公司

DOI:10.32629/hwr.v3i2.1890

[摘 要] 灌浆施工技术是水库施工建设中最常使用的技术类型。在水库工程施工中,必须重视灌浆施工技术在水库施工中的 有效运用, 从而提高水库工程的整体质量,确保水库工程的使用性能和使用周期。本文主要对灌浆施工技术在水库施工中的应 用进行了探讨,仅供参考。

[关键词] 灌浆施工技术; 水库施工; 应用

随着社会经济的发展, 水利工程建设脚步也随之加快, 但是由于地质条件等因素的限制, 使得水利工程建设存在较 多棘手问题, 尤其是对水库工程建设来说复杂地层条件, 增 加了渗漏的可能性, 严重阻碍了水库建设性能的发挥。而灌 浆施工技术的应用则可以强化水库工程的防渗效果, 提高地 基质量, 因此加强对其应用研究显得尤为重要。

\section{1 简述灌浆施工技术的原理和作用}

\section{1 原理}

灌浆施工技术是水库工程建设中最常使用的技术类型, 其目的是增强水库的防渗加固效果, 防止险情的发生。其具 体工作原理是: 在水库坝基施工中, 利用压力设备将粘土浆 防渗材料注入到堆石体水库大坝基础中, 实现对堆石体缝隙 大坝基础缝隙的填充。通过灌浆施工技术的有效应用, 能够 有效避免坝基结构松动等问题, 提升水库坝基的稳定性和安 全性, 保证整个水库工程的建设质量。

\section{2 作用}

在水库工程建设中, 应用灌浆施工技术的主要作用有:

\subsection{1 固化作用}

灌浆作业中所使用的水泥材料可以同结构中的其他材 料发生一定的化学反应, 进而产生一种新的岩体结构, 增加 水库坝基结构的坚固性和强度。例如水泥可以同松软的材料, 如地下土层中的黏土等发生某种化学反应生成类岩体, 增大 整体的坚硬度。

\subsection{2 压密作用}

将混合浆液注入到堆石体砂砾石地层中时, 其会对地层 产生一定的挤压, 从而压实地层中的细小颗粒, 并通过与混 合浆液的融合、挤压, 使其形成一个较为严密的地层结构, 减少缝隙的存在, 强化地层的整体效果。

\subsection{3 填充作用}

通过浆液的注入可以将地层中存在的缝隙进行有效填 充, 阻隔水流的通过, 增强地层的密实性。

1.2. 4 粘合作用

由于浆液自身具有较强的凝胶效果, 能够将松动的土层 或者存在缝隙的结构有效粘合起来, 以此增强结构的承载力, 防止渗漏等问题的发生。

\section{2 灌浆施工技术在水库施工中的具体应用}

2.1 岩溶地区的应用

在岩溶地区开展水库工程建设时, 工作人员通常会通过 冲洗高压水泥灌浆的方式和普通灌浆技术开展施工作业, 以 保证水库工程建设的质量和安全。使用高压水泥灌浆方式的 优点在于:

首先, 通过高压水泥灌浆技术能够有效强化水库工程的 防渗效果; 其次, 该技术在实际应用过程中, 水泥在土层中会 呈现网状渗漏效果, 这对提高水库地基结构的抗裂变能力, 保证地基结构稳固性有着显著效果; 最后, 在岩溶地区, 通过 高压水泥灌浆施工技术的应用, 在钻机头部位置上安装喷嘴, 可以有效降低地下施工作业队的难度, 保证地下施工作业的 质量。

而使用普通灌浆技术的目的是将坝基施工中深层岩溶 中的杂质和其他填充物质有效排除, 促进水泥浆浴土层结构 之间的融合, 实现强化坝基整体结构的目的, 从而提高水库 工程施工质量。不过在使用该技术过程中, 施工人员必须对 设备和材料进行严格管控, 让其符合工程建设的具体要求, 避免渗流问题的产生。

\section{2 严重渗漏情况下的应用}

为了解决严重渗漏问题带来的影响, 在水库施工过程中, 通常会采用卵砾石层防渗帷幕灌浆施工技术、填充灌浆施工 技术和膜袋灌浆施工技术这三种。下面我们将逐一介绍这三 种灌浆施工技术的原理和作用

\subsection{1 卵砾石层帷幕灌浆施工技术}

该技术使用的主要原料有黏土和水泥, 按照合理配比将 两者有效混合并注入到堆石体中, 实现结构的固化, 增大结 构强度。一般在灌注作业中需要涉及应用到打管灌浆、循环 灌浆以及套阀式灌浆等方式。在现阶段防渗加固与勘探的水 库施工工作中, 这项灌浆技术起到补充的作用。在实际施工 作业前, 工作人员需要先对施工现场的水文、地质等资料信 息展开合理的收集, 并按照收集整合的材料以及施工要求科 学准备施工设备和用具, 如输浆系统、注浆机、压空机等, 并对使用的卵砾石材料实行破碎吸浆处理, 以保证灌浆施工 作业的有序开展。同时在灌浆操作中, 要按照自上而下的灌 
浆原则, 待其凝固好后再实施扫孔工作。通常情况下, 在凝固 后的 36-48 小时后在开始扫孔作业。

\section{2 .2 填充灌浆技术}

填充灌浆技术使用的主要原材料有三种, 一是砾石, 二 是水泥, 三是粗砂。在原材料选购过程中, 要对砾石的尺寸大 小予以合理控制。如果在选择的过程中, 砾石的大小没有达 到统一的标准, 则可以适当的采用粘稠度更高的水泥, 在具 体配料的过程中, 需要对配料的数量及材料进行灵活的运 用。而水泥材料的选择则需要重点关注其强度性能, 一般会 采用强度在 $32.5 \mathrm{Kgf} / \mathrm{cm}^{2} 325 \mathrm{kpa}$ 左右的水泥材料实行填充灌 浆作业。

由于目前市面上水泥材料的种类相对较多, 在水库工程 建设中, 为了保证灌浆施工效果, 一般会采用硅酸盐水泥或 者普通硅酸盐水泥。在应用填充灌浆技术之后, 施工人员需 要对灌浆水泥的细度与强度进行定期性的检查, 避免出现因 存放过久而受潮的情况。此外, 在灌浆施工结束后, 还需对土 体的渗漏系数进行准确测算, 且待灌浆作业完成后, 需要对 浆口凝结情况予以观察和控制, 尽可能保证待凝时间在 24 小时以上。

\subsection{3 膜袋灌浆施工技术}

该技术在应用过程中, 对于膜袋的质量和耐磨性能有着 严格要求。普通膜袋的主要组成材料有聚丙烯和尼龙, 但这 种材料的膜袋很难更好的满足工程建设的防渗要求。膜袋灌 浆的主要应用原理为:

将水泥与砂浆放置在模袋膜袋中, 膜袋中的水分会受到 膜袋的挤压作用而不断流失, 最后膜袋中留下了没有水分的 砂土与水泥, 这在极大程度上加速了砂浆的凝结时间, 并且 侧面地降低了水泥砂浆中的含浆量。耐磨性较高的膜袋具有 较好的束缚效果, 可以减缓袋中水泥和砂浆的流逝速度, 保 证其自身阻塞作用的充分发挥, 能够有效减少水库工程结构 的渗漏。不过在实际施工中, 还需要对挤压压力值进行合理 管控, 保证其与实际施工要求相符合, 以此来提升压实作业 的标准性、规范性, 提高灌浆压实工作的质量, 加强坝基结构 的稳固性。

\section{3 灌浆施工技术在水库施工中的应用建议}

3.1 加大施工人员综合素质的培训力度

在水库施工建设中, 施工人员是各项工作开展的基础, 也是保证施工质量和安全的基础, 因此应加大对施工人员的 培训力度, 不断完善施工人员的综合素质能力水平, 以此保 证施工作业的有序开展, 增强各项技术操作的标准性。首先, 企业需对施工人员进行专业的岗前培训, 让其明确施工的要 点和重点, 了解各项技术的操作标准和规范; 其次, 定期开展 专业技能和素质培训, 提高施工人员的综合能力水平; 最后,
开展安全教育工作, 让施工人员明确安全生产的重要性, 减 少水库施工中危险事故的发生, 维护工程建设安全, 为企业 带来更高效益。

3.2 提升坝基冒浆问题的处理效率

水库工程施工中, 坝基冒浆问题通常会出现在坝基底部 坝坡以及封口位置上, 施工人员需要针对不同的部位的冒浆 问题, 有针对性的制定合理解决措施, 减少冒浆问题对工程 质量的影响。在处理坝基底部的冒浆问题时, 需要对灌浆时 间间隔以及灌浆数量予以合理控制, 同时结合其他通道一起 开展填堵工作; 在处理坝坡部位的冒浆问题时, 则需要对原 有的灌浆施工方式予以调整, 并保证开挖回填工作的质量, 以减少冒浆的影响。如果该区域内的冒浆情况较为严重, 可 以在上述作业基础上, 通过多次或者间歇灌浆的方式改善处 理质量。针对封口部位的冒浆情况, 其通常都是由于坝基浆 液饱和造成的, 这时可以通过停止施工的方式予以解决。

3.3 制定合理的水利施工环境应急方案

气象因素作为影响水库工程建设的主要环境因素, 如果 不加大对其控制力度, 则会直接影响水库工程建设质量。因 此在实际施工作业前, 施工人员需要结合现场实际情况制定 合理的应急处理措施, 改善施工现场及其周边环境。同时, 对施工现场各项设施进行合理规划布局, 完善相应管理制度, 以加强水库施工现场的规范化, 优化水库工程建设水平。

3.4 坝基裂缝问题的处理

裂缝是坝基灌浆施工中最常出现的问题, 在对其处理前, 先要确定裂缝种类及程度, 如果出现的是纵向陷裂缝, 其影 响相对较小, 则可以在灌浆施工作业完成后再予以相应的处 理, 但如果是纵向䢃裂缝, 则需要立即停工完成处理工作, 待 裂缝闭合后方可开展后续施工作业。

\section{4 结语}

总之, 水库在人类社会发展中发挥着重要作用。随着水 库建设数量的不断增加, 其作用也日益凸显出来, 并成为现 今人们生活用水、工农业生产用水以及消防用水的主要补充 来源。基于此, 加大对水库工程建设质量的重视度, 合理应用 灌浆施工技术, 增大水库工程的施工安全系数就显得尤为重 要。希望通过上文的阐述能够为水库工程建设提供更多帮 助。

\section{[参考文献]}

$[1]$ 汪湖海.研究水库施工中灌浆施工技术的应用 [J].低 碳世界,2017(33):58.

[2]钟霖.浅谈灌浆施工技术在水库施工中的应用 [J].中 国水运,2018(05):59.

[3] 饶蕾. 水库施工中灌浆施工技术的应用 [J]. 居 舍,2018(08):60. 